Check for updates

Cite this: Chem. Sci., 2019, 10, 2732

๑ All publication charges for this article have been paid for by the Royal Society of Chemistry

Received 31st July 2018

Accepted 9th January 2019

DOI: $10.1039 / c 8 s c 03394 c$

rsc.li/chemical-science

\section{Ubiquitin binds the amyloid $\beta$ peptide and interferes with its clearance pathways $\uparrow$}

F. Bellia, ${ }^{a}$ V. Lanza, (D) a S. García-Viñuales, (D) a I. M. M. Ahmed, (D) a A. Pietropaolo, (D) b C. lacobucci, (D) c G. Malgieri, (D) d G. D'Abrosca, ID d R. Fattorusso, ID d V. G. Nicoletti, (DD e D. Sbardella, ${ }^{f}$ G. R. Tundo, ${ }^{f}$ M. Coletta, ${ }^{f}$ L. Pirone, $^{g}$ E. Pedone, (iD) $g$ D. Calcagno, ${ }^{h}$ G. Grasso (iD *h and D. Milardi iD *a

Several lines of evidence point to a compromised proteostasis associated with a reduction of the Ubiquitin Proteasome System (UPS) activity in patients affected by Alzheimer's Disease (AD) and suggest that the amyloid $\beta$ peptide $(A \beta)$ is an important player in the game. Inspired also by many reports, underlining the presence of ubiquitin ( $\mathrm{Ub}$ ) in the amyloid plaques of $A D$ brains, here we set out to test whether $\mathrm{Ub}$ may bind the $A \beta$ peptide and have any effect on its clearance pathways. By using an integrated array of MALDI-TOF/UPLC-HRMS, fluorescence, NMR, SPR, Microscale Thermophoresis (MST) and molecular dynamics studies, we consistently demonstrated that $A \beta 40$ binds Ub with a $1: 1$ stoichiometry and $K_{d}$ in the high micromolar range. In particular, we show that the $\mathrm{N}$-terminal domain of the $A \beta$ peptide (through residues $\mathrm{D} 1, \mathrm{E} 3$ and $\mathrm{R} 5$ ) interacts with the $\mathrm{C}$-terminal tail of $\mathrm{Ub}$ (involving residues $\mathrm{K} 63$ and $\mathrm{E} 64$ ), inducing the central region of $A \beta\left({ }^{14} \mathrm{HQKLVFFAEDVGSNK}{ }^{28}\right)$ to adopt a mixed $\alpha$-helix/ $\beta$-turn structure. ELISA assays, carried out in neuroblastoma cell lysates, suggest that $A \beta$ competitively binds $U b$ also in the presence of the entire pool of cytosolic Ub binding proteins. Ub-bound $A \beta$ has a lower tendency to aggregate into amyloid-like fibrils and is more slowly degraded by the Insulin Degrading Enzyme (IDE). Finally, we observe that the water soluble fragment A $\beta 1-16$ significantly inhibits Ub chain growth reactions. These results evidence how the non-covalent interaction between $A \beta$ peptides and Ub may have relevant effects on the regulation of the upstream events of the UPS and pave the way to future in vivo studies addressing the role played by $A \beta$ peptide in the malfunction of proteome maintenance occurring in AD.

\section{Introduction}

Alzheimer's disease (AD), the most common form of dementia worldwide, is an age-related, fatal neurodegenerative disorder.

${ }^{a}$ Consiglio Nazionale delle Ricerche, Istituto di Biostrutture e Bioimmagini, Via P. Gaifami 18, 95126 Catania, Italy.E-mail: danilo.milardi@cnr.it

${ }^{b}$ Dipartimento di Scienze della Salute, Università degli Studi Magna Graecia di Catanzaro, Viale Europa, 88100, Catanzaro, Italy

'Department of Pharmaceutical Chemistry \& Bioanalytics, Institute of Pharmacy, Martin Luther University Halle-Wittenberg, 06120 Halle/Saale, Germany

${ }^{d}$ Department of Environmental, Biological and Pharmaceutical Sciences and Technologies, University of Campania "Luigi Vanvitelli", Via Vivaldi 43, 81100 Caserta, Italy

${ }^{e}$ Dipartimento di Scienze Biomediche e Biotecnologiche (BIOMETEC), sez. Biochimica medica, Università di Catania, Via Santa Sofia 97, 95124 Catania, Italy

${ }^{f}$ Dipartimento di Scienze Cliniche e Medicina Traslazionale, Università di Roma Tor Vergata, Via Montpellier 1, 00133, Roma, Italy

${ }^{g}$ Consiglio Nazionale delle Ricerche, Istituto di Biostrutture e Bioimmagini, Via Mezzocannone, 16, Naples I-80134, Italy

${ }^{h}$ Dipartimento di Scienze Chimiche, Università di Catania, V.le Andrea Doria 6, 95125 Catania, Italy.E-mail: grassog@unict.it

$\dagger$ Electronic supplementary information (ESI) available. See DOI: $10.1039 / \mathrm{c} 8 \mathrm{sc} 03394 \mathrm{c}$
A hallmark of $\mathrm{AD}$ is the presence of extracellular proteinaceous deposits (senile plaques) in the brain of affected people. The prevalent component of senile plaques is $\beta$-amyloid $(\mathrm{A} \beta){ }^{1}$ Although a firm relationship between the occurrence of different $\mathrm{A} \beta$ aggregates in the $\mathrm{AD}$ brain and the severity of the disease has not been established yet, $A \beta$ misfolding and selfassembly are widely believed to be crucial pathogenic events in $\mathrm{AD}$ (amyloid hypothesis). ${ }^{2-4}$ Unfortunately, all clinical trials of amyloid-targeting drugs have failed so far ${ }^{5,6}$ suggesting that the amyloid hypothesis needs to be reconsidered. Intriguingly, several reports put in evidence that transgenic mice models of $\mathrm{AD}$ show an intracellular $\mathrm{A} \beta$ immunoreactivity ${ }^{7}$ which occurs before cognitive loss and massive amyloid plaques deposition and may be more closely associated with the disease progress. ${ }^{\mathbf{8}}$ Therefore, studies focusing on the interplay between $A \beta$ amyloid growth and protein clearance in the cell represent a promising arena for the design of more effective $\mathrm{AD}$ therapies. ${ }^{9}$

The removal of misfolded and potentially toxic cytosolic proteins is mostly regulated by the ubiquitin proteasome system (UPS). ${ }^{10}$ The first component of the UPS is ubiquitin (Ub), a small protein composed of 76 amino acids, with 
a compact globular structure characterized by a mixed parallel/ anti-parallel $\beta$-sheet packing against an $\alpha$-helix. ${ }^{11}$ Degradation of misfolded proteins by the UPS occurs first by labeling a lysine residue of the substrate with a (poly)ubiquitin tag (ubiquitinylation) which is specifically identified and degraded by the proteasome. ${ }^{12}$ When the UPS is not efficient, the removal of toxic protein assemblies gets slower and, in turn, the disease may progress more rapidly.

Consistent with this hypothesis, many reports suggest that the UPS malfunction plays a significant role in $A \beta$ accumulation and, in turn, in $\mathrm{AD}$ progress. ${ }^{13}$ However, the effects of $\mathrm{A} \beta$ on proteasome function are still under debate. In particular, on one hand, the $A \beta$ peptide has been observed to be a proteasome inhibitor on its own; ${ }^{14-21}$ on the other hand some studies have outlined how distinct $A \beta$ peptide assemblies may inhibit or even activate different proteasome particles. ${ }^{22}$ The controversial role of $A \beta$ in affecting proteasome function as well as the presence of Ub-positive proteinaceous aggregates in the senile plaques of $\mathrm{AD}$ patients ${ }^{23}$ suggests that UPS malfunction observed in $\mathrm{AD}$ could be then more likely linked to a failure of its upstream components (i.e., ubiquitinylation). ${ }^{24}$

Ubiquitinylation needs the coordinated activity of three distinct types of enzyme: (i) an ATP-consuming Ub-activating enzyme (E1); (ii) a Ub-conjugating enzyme (E2) and a Ub ligase (E3). ${ }^{25}$ Furthermore, the fact that these processes are largely governed by low-affinity interactions between Ub and the various Ub-writing enzymes (i.e., E1, E2 and E3) ${ }^{26}$ envisages the possibility that an excess of $\mathrm{A} \beta$ might inhibit, as a decoy effect, these processes through non covalent binding to Ub.

To test this hypothesis, here we use a battery of experimental (NMR, SPR, MST, cross-linking XL ESI-MS, MALDI-TOF MS) and in silico (MD) approaches to fully characterize the interactions of Ub with the $A \beta$ amyloid peptide in terms of stoichiometry, affinity and binding sites. Next, we employ an ELISA assay to evaluate if the interaction of $A \beta$ with $\mathrm{Ub}$ is detectable in cell lysates too, thus supporting the significance of this study in a biological context. These experiments are also paralleled by ESI-MS studies addressing $\mathrm{A} \beta$ hydrolysis by the Insulin Degrading Enzyme (IDE), a protease which is known to be involved in the physiological amyloid clearance. ${ }^{27}$ The effects of $\mathrm{Ub}$ on $\mathrm{A} \beta$ amyloid aggregation and Ub chain growth reactions are finally investigated.

\section{Results and discussion}

\section{NMR analysis of Ub in complex with $A \beta 40$}

In an attempt to assess if $\mathrm{Ub}$ binds $\mathrm{A} \beta$, we first analyzed $\mathrm{Ub} / \mathrm{A} \beta$ interactions in solution by NMR spectroscopy. Free ${ }^{15} \mathrm{~N}-{ }^{13} \mathrm{C}$ labeled Ub was characterized by means of a standard set of triple and double resonance experiments that constituted the reference spectra. There are two naturally occurring forms of the $A \beta$ peptide: $A \beta 42$ and $A \beta 40$. Although $A \beta 42$ is known to be more prone to form amyloid aggregates, $A \beta 40$ is produced more abundantly in the cell (A $\beta 40$ : A $\beta 42$ molar ratio is $9: 1)$ and thus may be more conveniently used to investigate interactions with $\mathrm{Ub}^{28}$ furthermore, the tendency of A $\beta 42$ to form aggregates makes it very problematic to carry out NMR experiments at very high concentrations. Unlabeled $A \beta 40$ was then added as a single aliquot of a known amount to the sample and a new set of spectra was recorded. The translational diffusion coefficient, chemical shift and intensity variations of the different nuclei in the presence and absence of $\mathrm{A} \beta$ were evaluated. The translational diffusion coefficient measured for Ub in the absence of the peptide is $1.33 \pm 0.12 \times 10^{-10} \mathrm{~m}^{2} \mathrm{~s}^{-1}$, consistent with values reported in the literature. ${ }^{29}$ The same coefficient measured in the presence of $\mathrm{A} \beta 40$ is $1.28 \pm 0.18 \times 10^{-10} \mathrm{~m}^{2} \mathrm{~s}^{-1}$. These coefficients allow us to rule out protein-protein aggregation phenomena mediated by $\mathrm{A} \beta 40$ within the NMR spectroscopic concentration range investigated and are in agreement with the interaction between the two molecules. The analysis of Ub HSQC after sub-stoichiometric A $\beta 40$ addition shows that the overall Ub fold is maintained, although a number of peaks are perturbed. As protein-ligand interactions correspond often to a redistribution of the protein internal dynamics, ${ }^{30-33}$ intensity changes of the amide cross-peaks in the $2 \mathrm{D}\left[{ }^{1} \mathrm{H},{ }^{15} \mathrm{~N}\right]-\mathrm{HSQC}$ spectra represent sensitive probes of exchange and/or relaxation rate variations of each protein residue upon interaction (see Fig. S1 in the ESI $\dagger$ ). Perturbation of signal intensities with respect to the reference spectra as a function of ligand addition thus provides useful dynamic and conformational information about the binding event. Mapping the differences in normalized signal intensities onto the Ub structure (PDB code: 1UBQ; Fig. 1 upper panel) outlines a region influenced by the interaction with $\mathrm{A} \beta 40$, which involves residues belonging to the C-terminal tail and the $\beta$ sheet of the molecule, leading to a loss in intensity of their HSQC cross-peaks (Fig. 1 lower panel). The residues composing the helix appear not to be involved in the interaction as their cross-peaks are less influenced by the presence of the peptide in solution.

\section{Molecular modeling of $\mathrm{Ub} / \mathrm{A} \beta$ complexes}

NMR analysis provides molecular details about the Ub residues directly involved in the interaction with $\mathrm{A} \beta$. These data are used as a starting point to describe, at an atomistic level, the Ubbound conformation of $\mathrm{A} \beta$ by molecular modeling. Upon $\mathrm{A} \beta 40$ interaction with $\mathrm{Ub}$, three main binding poses may be disclosed (Fig. 2A). The first binding pose features a network of salt-bridges involving the N-terminal section of $\mathrm{A} \beta 40$, with residues D1, E3 and K28 facing the Ub K6 residue (Fig. 2A(a)). This interaction triggers hydrophobic contacts between the Ub central region and $\mathrm{A} \beta 40$, which mainly adopts turn conformations with a short $3_{10}$ helix involving the ${ }^{16} \mathrm{KLV}^{18}$ segment. At variance with the latter binding surface, in the second binding pose, the $\mathrm{N}$-terminal domain of $\mathrm{A} \beta 40$ faces the Ub C-terminal region. Herein, A $\beta 40$ residues D1, E3 and R5 contact Ub residues K63 and E64, perturbing the typical salt-bridge network featuring the free Ub structure (Fig. 2A(b)). The central region of $\mathrm{A} \beta 40$ is less prone to interact with $\mathrm{Ub}$ owing to the intramolecular interactions building an $\alpha$-helix in the ${ }^{14}$ HQKLVFFAEDVGSNK ${ }^{28}$ segment. In the third binding pose, the A 340 charged N-terminal amine of D1 faces residue E64 of Ub (Fig. 2A(c)). Even in this binding pose, the salt-bridge between $\mathrm{K} 63$ and $\mathrm{E} 64$ is affected by the N-terminal amine 

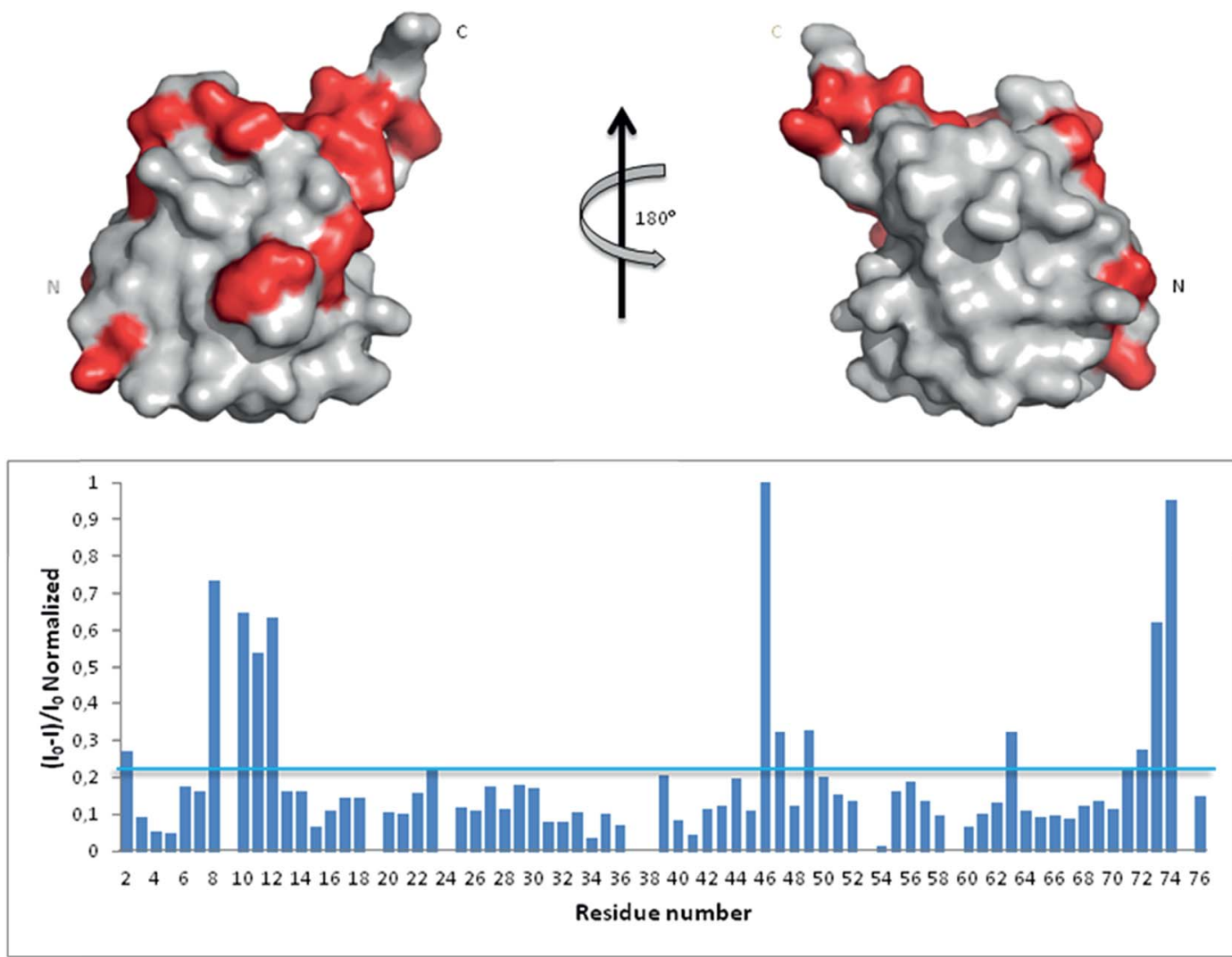

Fig. 1 Upper panel: mapping onto the Ub structure of the intensity variations of the ${ }^{1} \mathrm{H}$ and ${ }^{15} \mathrm{~N}$ amide cross-peaks after the addition of $\mathrm{A} \beta 40$ defines a neat region of the peptide interaction. The residues whose peaks were reduced in intensity are represented in red. Lower panel: ${ }^{1} \mathrm{H}$ and ${ }^{15} \mathrm{~N}$ amide cross-peaks intensity variations of the Ub HSQC spectrum after the addition of $30 \mu \mathrm{M} A \beta 40$ reported as a function of protein residue numbers.

group. Furthermore, D23 comes in contact with R42 which is close to R72, perturbing the typical network of the charged arginine residues of the Ub structure. The central region of A $\beta 40$ is involved in a loop, forming a small $\beta$-turn, which involves the segments ${ }^{16} \mathrm{KL}^{17}$ and ${ }^{35} \mathrm{MV} .{ }^{36}$ On the whole, the $\mathrm{A} \beta 40 \mathrm{~N}$-terminal domain interacts with both the $\mathrm{N}$ - and $\mathrm{C}$-terminal regions of $\mathrm{Ub}$ triggering subtle variations in the $A \beta$ central domain which folds in $\alpha$-helical structures resembling those observed elsewhere for membrane-bound $A \beta$ peptides. ${ }^{34}$ Notably, molecular modeling suggests that the Ub binding induces significant structural constraints along the region encompassing the hydrophobic Phe residues of $\mathrm{A} \beta$.

Cross-linking experiments. Chemical cross-linking/mass spectrometry (XL-MS) is a well-established tool that allows gaining insights into protein conformations and proteinprotein interactions. ${ }^{35-38}$ It relies on creating distance constraints between cross-linked amino acid side chains that can be further used to derive protein structures. Cross-linking can involve two residues belonging to a common protein or to different proteins of a supramolecular complex. In this study disuccinimidyl dibutyric urea (DSBU) ${ }^{39}$ has been used as homobifunctional cross-linker. Its succinimidyl ester (NHSester) head groups can react with the nucleophilic side chains of Lys, Ser, Thr, and Tyr, and with the N-terminus of proteins fixing their spatial arrangement. The cross-linked proteins and protein assemblies can be subsequently studied by mass spectrometry (MS) following a bottom-up approach. Such a process allows to unambiguously identify the cross-linked amino acids, proving their proximity in the native structure of the protein assembly. ${ }^{40}$ Cross-linking experiments of $\mathrm{Ub}$ in the presence of $\mathrm{A} \beta 40$ have been performed at $\mathrm{pH} 8$ and DSBU has been employed as a reagent for covalently bridging Lys, N-termini, Ser, Thr, and Tyr, which lie within a $\mathrm{C} \alpha-\mathrm{C} \alpha$ distance range of 27 A. Cross-linked samples were subjected to a proteomic analysis following a bottom-up approach and data were scrutinized with MeroX software. Several intra- and inter-molecular crosslinks have been identified for the Ub/A $\beta 40$ complex. Thirteen unique intramolecular Ub cross-links (Table S1 in ESI $\dagger$ ) were mapped onto its X-ray structures (PDB code 1UBQ, $1.8 \AA$ resolution). ${ }^{11}$ The relevant measured Euclidean $\mathrm{C} \alpha-\mathrm{C} \alpha$ distances measured fall within the range of 6.2 to $20.2 \AA$ with an average of $15.3 \AA$ and are fully consistent with the known 3D arrangement of Ub. Intra-molecular $A \beta 40$ cross-links were not considered for deriving structural information. In fact, it is not possible to distinguish between inter- and intra-molecular cross-links of $A \beta 40$ as oligomeric $A \beta 40$ aggregates may be present in solution during the cross-linking reaction. Four intermolecular cross-links were found between $\mathrm{Ub}$ and $\mathrm{A} \beta 40$. Interestingly, they exclusively involve the N-terminal region of $\mathrm{A} \beta 40$. In particular, $\mathrm{A} \beta 40 \mathrm{D} 1$ was found to be connected to K48 


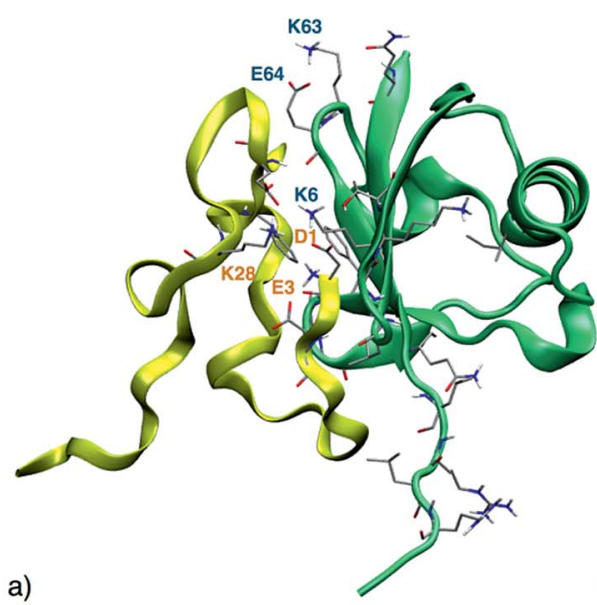

b)

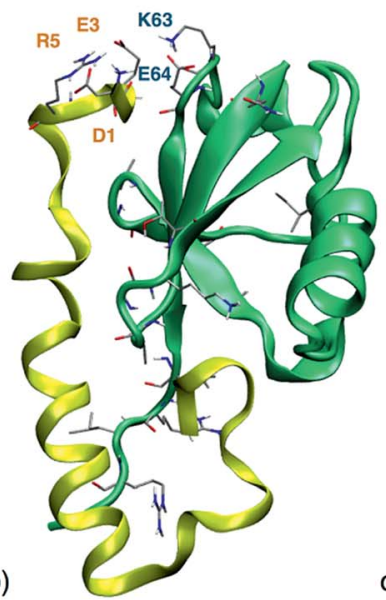

A

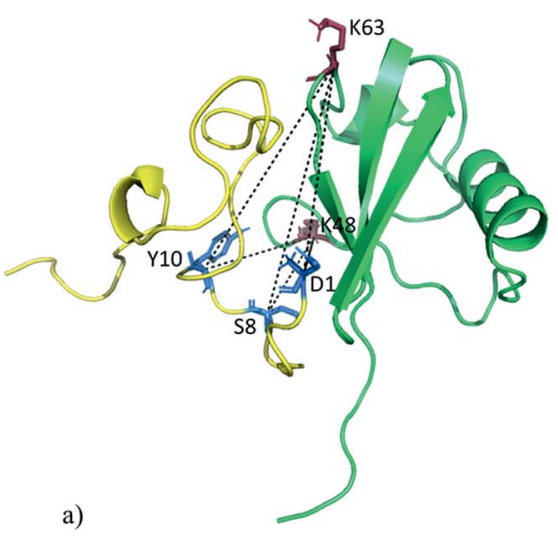

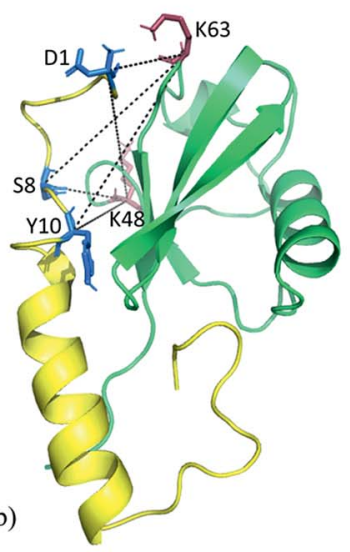

B
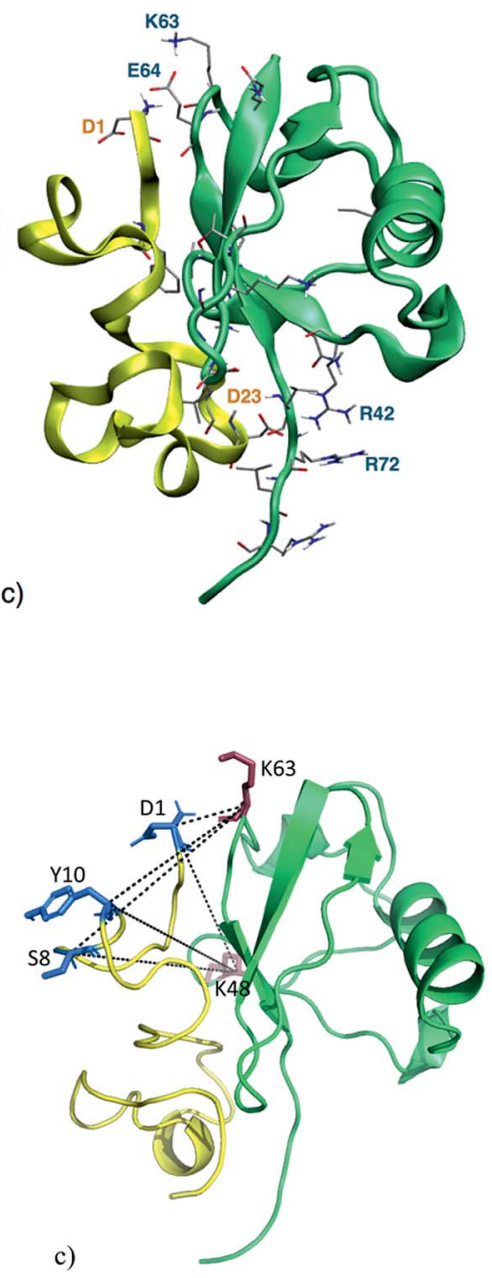

c)

Fig. 2 Panel A: the three lowest energy binding modes for the $A \beta 40 / \mathrm{Ub}$ complex. A 340 sections are shown by yellow ribbons, Ub sections are shown by green ribbons. The residues of $\mathrm{Ub}$ interacting with $\mathrm{A} \beta 40$ are shown by solid sticks and those involved in salt-bridge interactions are also labeled. The internal energies of the $A \beta 40 / \mathrm{Ub}$ complex in the three binding poses (a)-(c) are $-4490 \mathrm{kcal} \mathrm{mol}^{-1},-4404 \mathrm{kcal} \mathrm{mol}^{-1}$ and $-4271 \mathrm{kcal} \mathrm{mol}{ }^{-1}$, respectively. Panel B: DSBU cross-links mapped onto the three lowest energy binding modes for the AB40/Ub complex. A 40 sections are shown in yellow, Ub sections are shown in green. The cross-linked residues of A $\beta 40$ are shown by blue solid sticks and cross-linked residues of Ub are represented as red solid sticks. All the measured $\mathrm{C} \alpha-\mathrm{C} \alpha$ Euclidean distances are shorter than $27 \AA$ as required by the DSBU cross-linker.

and K63 of Ub. The other two bridges were found between S8 or Y10 of A 340 and K48 and K63 of Ub. The targeted residues (S8 or Y10) of $A \beta 40$ could not be assigned unambiguously. These cross-links were mapped onto the three 3D structure models of the Ub/A $\beta 40$ complex disclosed by theoretical calculations (Fig. 2B). In all three binding poses the measured Euclidean $\mathrm{C} \alpha-$ $\mathrm{C} \alpha$ distances are $<27 \AA$, in agreement with distances that DSBU can connect. Interestingly, the overall surface of Ub predicted to interact with $\mathrm{A} \beta 40$ is confirmed. However, the cross-links involving K63 partially tunnel the protein chains in pose "a" and can be explained only by a high $\mathrm{A} \beta 40$ flexibility. Conversely, all cross-links are fully consistent with the calculated binding poses "b" and "c" (Fig. 2A). These results mainly support the proposed binding poses " $\mathrm{b}$ " and "c" suggesting a structural organization of the Ub/A $\beta 40$ complex where the $\mathrm{N}$-terminal part of $A \beta 40$ is in close proximity to the salt-bridge between K63 and
E64 in Ub. The binding of $\mathrm{A} \beta 42$ with Ub disclosed through molecular simulations suggests fewer non-covalent interactions than those detected in the binding of $A \beta 40$ with Ub. In particular, the salt-bridge network involving D1, E3 and K28 residues and the $\mathrm{K} 6$ residue of $\mathrm{Ub}$ is herein replaced by a salt-bridge interaction involving D11 or D7 with K6. Furthermore, the salt-bridge interaction between $\mathrm{K} 63$ and E64 of Ub remains unperturbed in the presence of $A \beta 42$ and no charged residue of A 342 appears in contact with R42 or R72 of Ub (see Fig. S2 in the $\mathrm{ESI} \dagger)$.

\section{Measurement of dissociation constants $\left(K_{d}\right)$ of the $A \beta 40 / \mathrm{Ub}$ complex}

The majority of known Ub binding partners are characterized by affinities in the micro-molar range $\left(2 \mu \mathrm{M}<K_{\mathrm{d}}<500 \mu \mathrm{M}\right) .{ }^{41}$ Here, 
to evaluate the binding affinity of $A \beta$ to $\mathrm{Ub}$, we performed SPR analysis on immobilized $A \beta 40$. Ub solutions were prepared by dissolving the protein in $10 \mathrm{mM}$ PBS (pH 7.4)/Tween $20(0.05 \%)$ and the injections were carried out in a serial configuration for 5 minutes at $20 \mu \mathrm{lmin}^{-1}$ and $30 \mu \mathrm{min}^{-1}$, respectively. Different concentration solutions of Ub $(43 \mu \mathrm{M}, 86 \mu \mathrm{M}, 171 \mu \mathrm{M}, 343 \mu \mathrm{M}$, and $755 \mu \mathrm{M}$ ) were prepared and after each injection a regeneration step was achieved using $\mathrm{NaCl} 2 \mathrm{M} / \mathrm{NaOH} 10 \mathrm{mM}$ (30

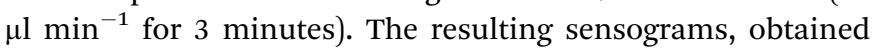
after reference subtraction, were extracted with MP-SPR Navi Data viewer analyzed through the Trace Drawer ${ }^{\mathrm{TM}}$ software and kinetic parameters of the interaction between $\mathrm{Ub}$ and $\mathrm{A} \beta$ were calculated. Panel A of Fig. 3 represents the overlay between experimental curves and fitted ones, while in Fig. S3 in the ESI $\dagger$ the fitting residual value graph is shown. The fitting model adopted was "OneToOne", which describes one monovalent ligand binding to one target. In this case, the following equation can be assumed to describe the biomolecular interactions:

$$
\mathrm{d} Y / \mathrm{d} t=\left(k_{\mathrm{a}} \times c-k_{\mathrm{d}}\right) \times Y
$$

where $Y$ is the recorded signal $(Y(t=0)=0), c$ is the concentration of the ligand in the bulk liquid, $t$ is the time in seconds, $k_{\mathrm{a}}\left[\mathrm{M}^{-1} \mathrm{~s}^{-1}\right]$ is the association rate constant and $k_{\mathrm{d}}\left(\mathrm{s}^{-1}\right)$ is the dissociation rate constant. Fitting parameters are reported in Table $\mathrm{S} 4$ in the ESI, $\uparrow$ where $B_{\max }$ represents the maximum

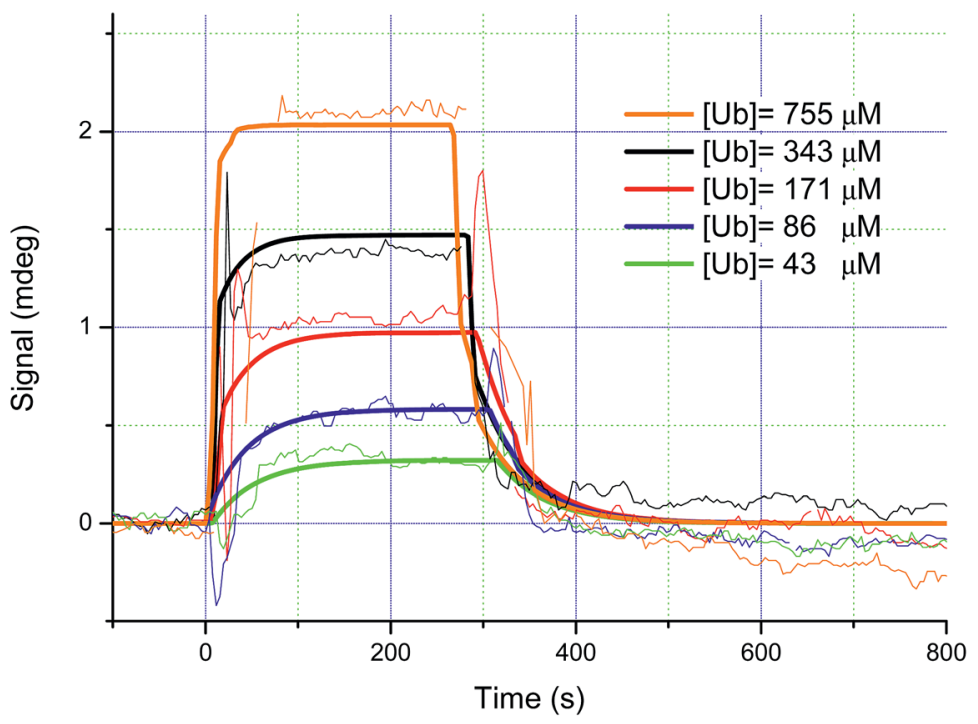

A
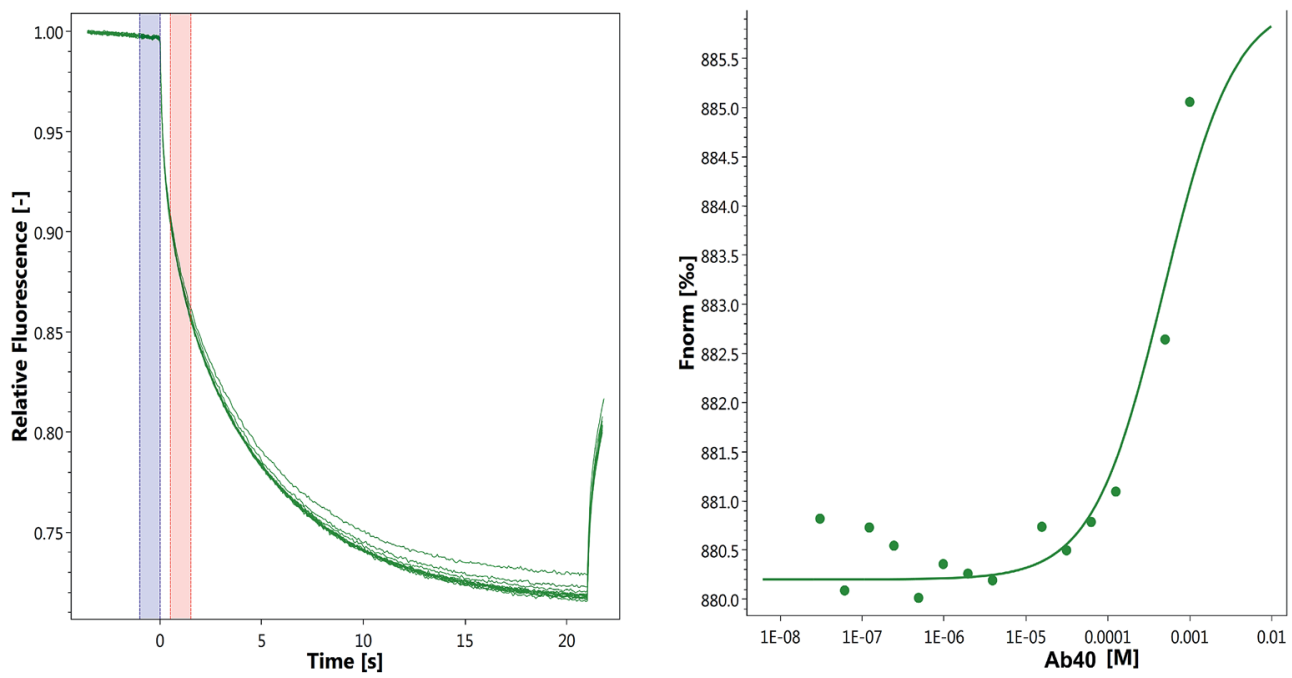

B

Fig. 3 Panel (A): sensograms (thin lines) and fitted curves (bold lines) of ubiquitin interacting with immobilized Aß40. Five concentrations of ubiquitin were injected: $43 \mu \mathrm{M}$ (green lines), $86 \mu \mathrm{M}$ (blue lines), $171 \mu \mathrm{M}$ (red lines), $343 \mu \mathrm{M}$ (black lines), and $755 \mu \mathrm{M}$ (orange lines). Panel (B): MST traces (left) of titrations of $A \beta 40$ against ubiquitin; $F_{0}$ (blue bar) and $F_{1}$ (red bar) correspond to the fluorescence of unbound state and bound state, respectively. Plot of normalized fluorescence (right) obtained from Ub binding experiments versus A 340 at different concentrations (from $20 \mathrm{nM}$ to $1 \mathrm{mM})$. 
signal, dependent on the number of receptors. All four fittings converge to the same kinetic parameters and reveal that $\mathrm{A} \beta$ binds Ub with a $K_{\mathrm{d}}=3.56 \times 10^{-4} \mathrm{M}$. In order to confirm that the $K_{\mathrm{d}}$ value obtained by SPR is not due to artifacts intrinsically linked to the SPR approach (immobilization of the $A \beta 40$ on a solid substrate), it could be advantageous to evaluate the Ub/A $\beta$ binding constants also by an independent technique. Microscale thermophoresis (MST) is a technology for the biophysical analysis of interactions between biomolecules. MST is based on the detection of a temperature-induced change in fluorescence of a target as a function of the concentration of a non-fluorescent ligand. Normalized fluorescence $\left(F_{\text {norm }}\right)$ is used to quantify binding via MST : $F_{\text {norm }}=F_{1} / F_{0}$ where $F_{0}$ refers to the initial fluorescence and $F_{1}$ is the fluorescence measured several seconds after the IR-laser has been turned on, when the traces of unbound and bound states can be discriminated. Plotting these values against the ligand concentration results in a typical binding isotherm providing the affinity constant value of the interaction.

First, we carried out MST experiments to measure $K_{\mathrm{d}}$ for Ub binding to $A \beta 40$ (see Fig. 3 panel $B$ ). Next, to rule out any possible bias due to amyloid aggregation, we also analysed $A \beta_{1-}$ 16 , a short soluble fragment that is thought to encompass the residues of the amyloid peptide involved in Ub interaction (see Fig. S4 in the ESI $\dagger$ ). We found that Ub is able to bind both the molecules with a comparable $K_{\mathrm{d}}\left(K_{\mathrm{d}} \mathrm{A} \beta 40=4.8 \times 10^{-4} \mathrm{M}\right.$ and $\left.K_{\mathrm{d}} \mathrm{A} \beta_{1-16},=3.4 \times 10^{-4} \mathrm{M}\right)$ in agreement with SPR data.

\section{A $\beta$ competitively binds $\mathrm{Ub}$ in whole cell extracts}

SPR and MST analysis have demonstrated that A $\beta$ binds Ub with a binding affinity which is comparable with that observed for many other Ub binding proteins. ${ }^{40}$ Therefore, our next step was to confirm if $\mathrm{A} \beta$ may competitively bind $\mathrm{Ub}$ also in the presence of the complete pool of cellular Ub binding partners. To this aim, we investigated the interaction of $U b$ with the $A \beta$ peptide in the presence of whole cell extracts from previously differentiated SHSY5Y neuroblastoma cells. Enzyme-linked immunosorbent assay (ELISA) is a convenient method widely employed to analyze protein-protein interactions in complex biological mixtures. Here, we employ an ELISA inhibition procedure, using alternatively $\mathrm{Ub}$ or $\mathrm{A} \beta 40$ as the solution binding partner to demonstrate that $\mathrm{A} \beta$ maintains its ability to bind $\mathrm{Ub}$ also in the presence of all natural cytosolic Ub binding partners (Fig. 4). The A $\beta$ peptide binding to the Ub-coated well surface shows an overwhelming increase of the signal over the control. In this case, the presence of cell lysates reduced the $\mathrm{A} \beta 40$ binding to Ub by about $50 \%$, thus demonstrating that Ub binds $A \beta$, albeit with a reduced signal intensity, and that this interaction is physiologically relevant, since it occurs also in the presence of the complete pool of cellular Ub binding partners. In a second control experiment, Ub binding to the A $\beta 40$ peptide immobilized on the well surface of the ELISA plate shows a significantly increased signal too (Fig. S5 in the ESI $\dagger$ ). As in the previous experiment, the binding is counteracted by the presence of cell lysates thus demonstrating that $\mathrm{A} \beta$ may competitively binds $\mathrm{Ub}$ also in the presence of all cytosolic components.

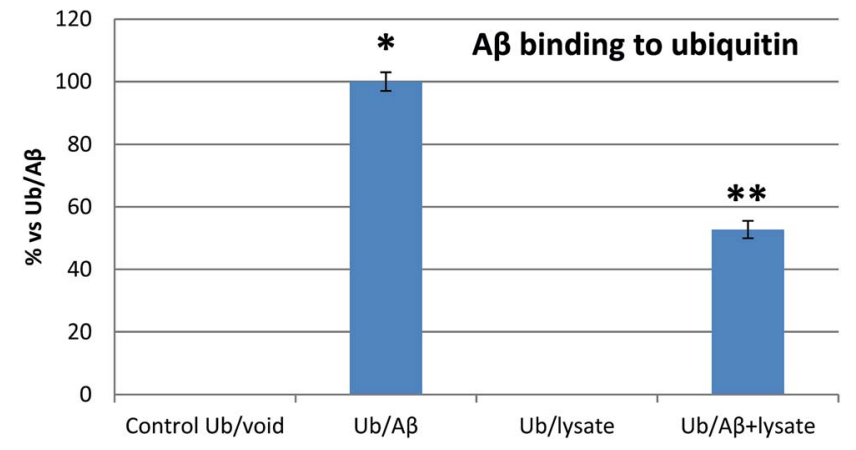

Fig. 4 Inhibition ELISA histograms for different $A \beta$ solutions (Ub/void: buffer; Ub/A $: 10 \mu M A \beta$ in buffer solution; Ub/Lys: whole cell lysates; $A \beta / U b+$ Lys: $10 \mu M A \beta$ in cell lysates) added to Ub-coated microwells. Significant differences from control values were indicated by $(p<0.05)$ * (vs. control) ** (vs. lysate competition) (one-way ANOVA with Tukey's post hoc test). Normalized data are reported as percentages considering $100 \%$ as the signal referring to the $\mathrm{Ub} / \mathrm{A} \beta$ solution.

\section{The proteolytic activity of IDE versus $A \beta 40$ is altered by Ub}

Once established that $A \beta$ may bind $U b$ in the cytosol, it is important to evaluate how this interaction may interfere with the physiological peptide clearance. The cellular homeostasis of $\mathrm{A} \beta$ is regulated by several proteases and degrading systems ${ }^{\mathbf{4 2}}$ among which IDE gives a particularly important contribution to the clearance of amyloidogenic peptides ${ }^{43}$ including $\mathrm{A} \beta$, amylin and insulin. ${ }^{44-47}$ Thus, any substance that somehow interacts with $\mathrm{A} \beta$ under physiological conditions could reasonably affect its IDE-mediated hydrolysis. In this context, the dosedependent effect of Ub on the IDE-catalyzed hydrolysis of $A \beta$ has been evaluated through a proteomic approach based on Ultra Performance Liquid Chromatography (UPLC) coupled with High Resolution Mass Spectrometry (HRMS). The enzymatic degradation of the amyloid peptide produced nine peptide fragments within $60 \mathrm{~min}$ of reaction (Table S3 in the ESI $\dagger$ ). As previously described, ${ }^{48}$ in the early stage of the IDEmediated hydrolysis, the main targeted regions encompass the hydrophobic Phe residues, the vicinal His residues, and, to a lesser extent, Asn27 and Met35 (Fig. 5A). By means of the LCMS analysis, all complementary peptide fragments adjacent to each cleavage site have been detected. The total amount of the full length substrate (i.e., A $\beta 40$ ) clearly decreases over the reaction time (Fig. 5B) such that after $20 \mathrm{~min}$ of reaction the concentration of $A \beta 40$ is $28 \%$ relative to the initial value and drops down to $5 \%$ after $30 \mathrm{~min}$. Such a trend is maintained when Ub was added to the reaction mixture but it is noteworthy that the rate of signal decrease is affected by Ub in a dosedependent manner (Fig. 5B). When the Ub : A $\beta 40$ molar ratio is $0.5: 1$, the residual substrate is $32 \%$ after 30 minutes with respect to the starting condition. Finally, $56 \%$ of $A \beta 40$ is still present after $60 \mathrm{~min}$ of reaction at the highest Ub : A $\beta 40$ molar ratio tested $(3: 1)$. Although the documented interaction between IDE and $\mathrm{Ub}^{49}$ does not rule out the possibility that Ub itself might somewhat affect IDE proteolytic activity, data shown in Fig. 5 represent a clear evidence in favor of an inhibitory effect by the non-covalent interaction between $\mathrm{Ub}$ 

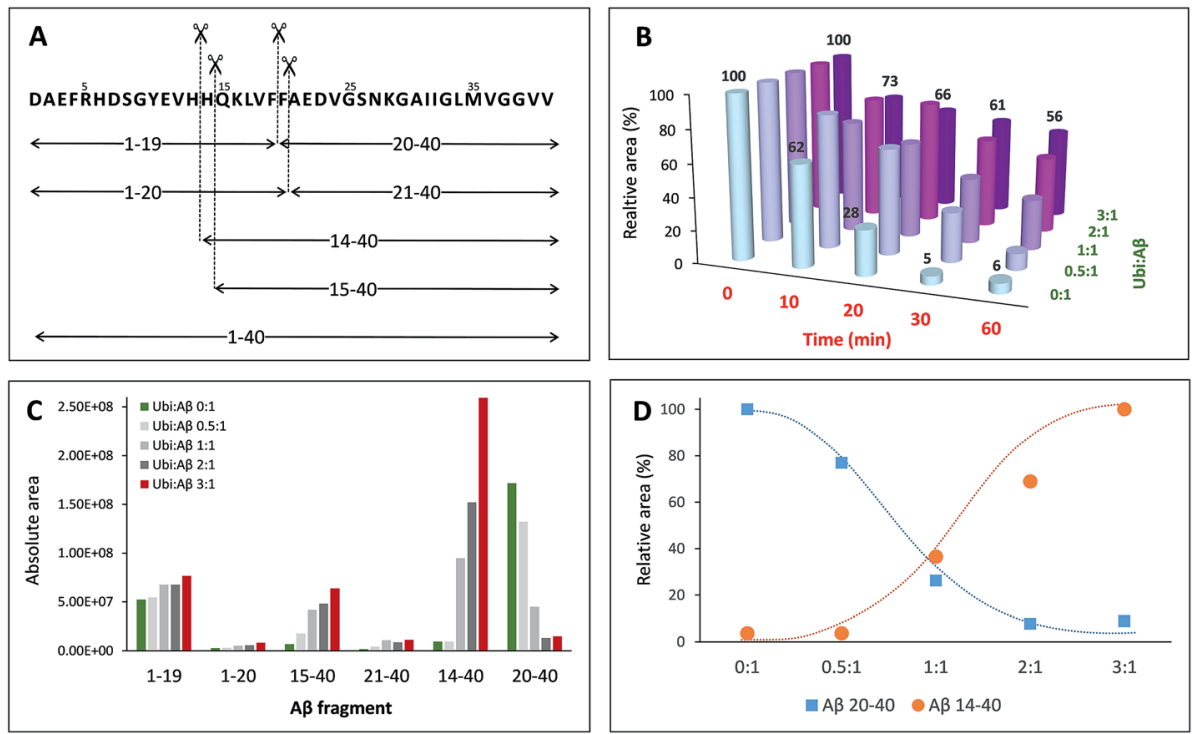

Fig. 5 Dose-dependent effect of ubiquitin on the hydrolysis of $A \beta 40$ catalysed by IDE. (A) Schematic of the IDE-induced hydrolytic pattern of $\mathrm{A} \beta 40$ at $37^{\circ} \mathrm{C}$ after $1 \mathrm{~h}$ of reaction. (B) Relative amounts of $A \beta 40$ (with respect to the initial one) as a function of the reaction time and of the $\mathrm{Ub}$ : $\mathrm{A} \beta 40$ molar ratio. Amounts of all the digested peptide fragments (C) or only $A \beta_{14-40}$ and $A \beta_{20-40}(\mathrm{D})$ as a function of the Ub : $A \beta 40$ molar ratio.

and $\mathrm{A} \beta 40$ on the IDE-mediated hydrolysis of $\mathrm{A} \beta 40$, in accordance with other experimental approaches adopted throughout this paper. In order to elucidate the regions of the $A \beta$ sequence mainly involved in the interaction with $\mathrm{Ub}$, the amount of all peptide fragments was reported as a function of the Ub : A $\beta 40$ molar ratio (Fig. 5C). In the absence of Ub (green bars) and in samples collected after $60 \mathrm{~min}$ of reaction, the chromatographic peaks having the higher intensity are those related to the complementary peptides $A \beta_{1-19}$ and $A \beta_{20-40}$, whereas $A \beta_{1-20}$, $\mathrm{A} \beta_{21-40}, A \beta_{14-40}$ and $A \beta_{15-40}$ are barely detectable. Increasing amounts of Ub had a very small effect on the concentration of $\mathrm{A} \beta_{1-20}$ and $\mathrm{A} \beta_{21-40}$; only a slight increase was observed for $\mathrm{A} \beta_{1-}$ ${ }_{19}$, whilst the concentration of $A \beta_{14-40}, A \beta_{15-40}$ and $A \beta_{20-40}$ was greatly affected by the presence of $\mathrm{Ub}$ in a dose-dependent manner. In particular, the formation of $A \beta_{15-40}$ (and even more of $A \beta_{14-40}$ ) is activated by the presence of $\mathrm{Ub}$, whereas the formation of $A \beta_{20-40}$ is greatly inhibited proportionally to the concentration of $\mathrm{Ub}$. The opposite trend, relative to the amounts of these peptide fragments formed at the various peptide : Ub ratios, is evident in Fig. $5 \mathrm{D}$.

The non-covalent interaction between $\mathrm{A} \beta$ and $\mathrm{Ub}$ has a clear site-specific effect on the IDE-mediated hydrolysis of $\mathrm{A} \beta$. The trend related to the formation of peptide fragments indeed suggests that Ub somehow inhibits the cleavage of the Phe19Phe20 peptide bond. Such an effect of Ub on the degradation pathway of $A \beta$ is in accordance with molecular models, described above (see Fig. 2), showing significant structural restraints, occurring upon Ub binding, in $\mathrm{A} \beta$ regions encompassing the central hydrophobic cluster (14-28 residues). The strong activation of the enzymatic hydrolysis at His13-His14 and His14-Gln15 might be considered a natural consequence of the inhibition involving the vicinal Phe residues. Indeed, $\mathrm{A} \beta_{14-40}$ and $\mathrm{A} \beta_{15-40}$ are also processed by IDE to form $\mathrm{A} \beta_{20-40}$; therefore, their own Ub-dependent accumulation is reasonably considered a consequence of the effect of $\mathrm{Ub}$ on the formation of $A \beta_{20-40}$. It is noteworthy that the crossing point between the Ub-induced increase of $A \beta_{14-40}$ and the concomitant decrease of $\mathrm{A} \beta_{20-40}$ is reached when the $\mathrm{Ub}: \mathrm{A} \beta$ molar ratio is $1: 1$. This evidence indeed strongly supports the $1: 1$ stoichiometry of the $\mathrm{Ub}$ : A $\beta$ complex evidenced by all other experiments (NMR, XLMS, SPR, MST and modeling). The $1: 1 \mathrm{Ub}: \mathrm{A} \beta$ adduct has also been observed by MALDI-TOF measurements (Fig. 6). The molecular weight of the $1: 1$ adduct was detected in all samples containing both the amyloid peptide and Ub (Fig. 6, left graph). Moreover, the higher the Ub : A $\beta$ molar ratio, the higher the absolute intensity of the mono-charged peak detected in linear mode, as a direct consequence of the amount of the complex formed. As a further confirmation of the peak attribution, these peaks drop down in the presence of IDE and proportionally to the reaction time, regardless of the $\mathrm{Ub}: \mathrm{A} \beta$ molar ratio (Fig. 6, right graphs). This trend can only be ascribed to a Ub-related inhibition of $\mathrm{A} \beta$ hydrolysis by IDE. These results coupled also with the finding that $A \beta$ is a proteasome inhibitor (see Fig. S6 in the ESI $\dagger$ ) support the hypothesis that excess A $\beta$ may significantly affect protein clearance pathways.

\section{Ub interferes with $A \beta$ amyloid growth}

It is known that $A \beta$ aggregation starts intracellularly, ${ }^{50}$ likely during abnormal interactions with lipid membranes. ${ }^{51-53}$ In order to investigate if the interaction between the amyloid peptide and ubiquitin modifies the well-known propensity of $A \beta$ to aggregate into amyloid-like fibers, the amyloid aggregation of $\mathrm{A} \beta$ was monitored by using a switch-on fluorescent dye (ThT). The experimental data obtained by the kinetic measurements were properly fitted to the theoretical aggregation models 


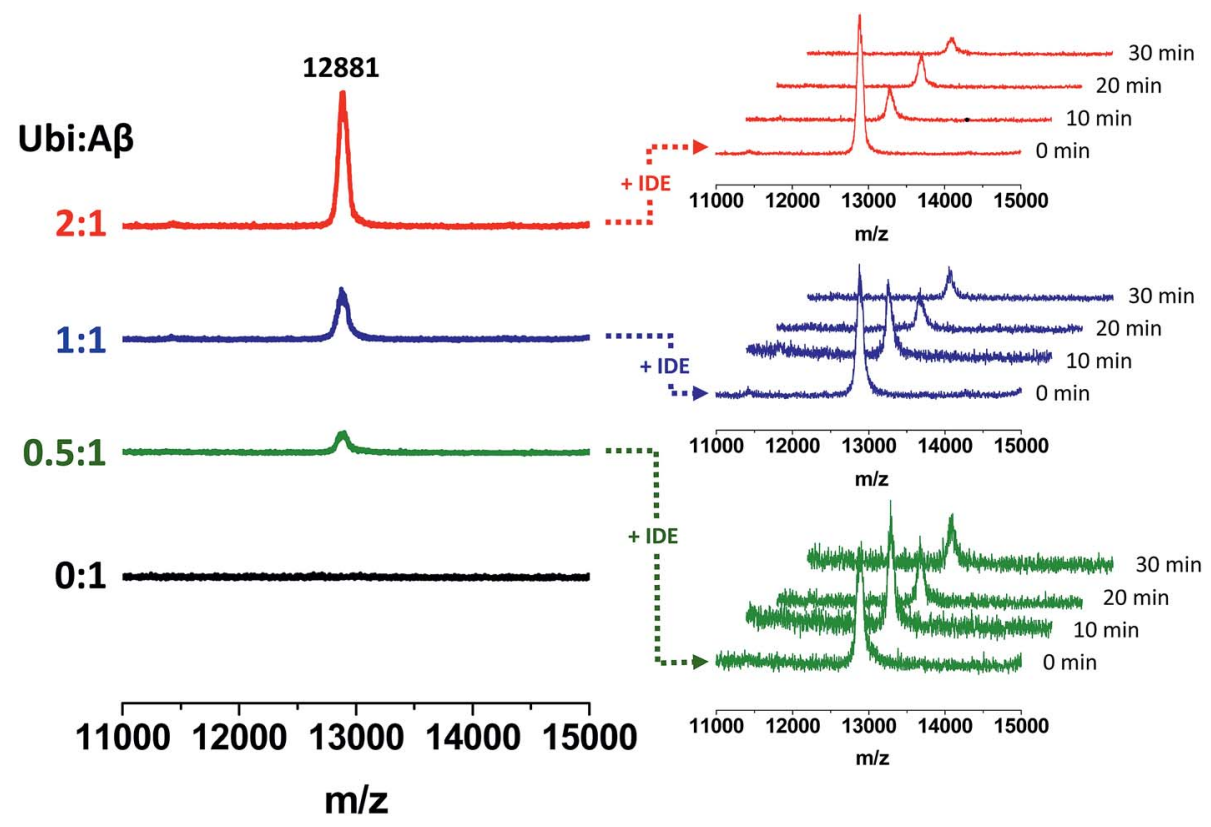

Fig. 6 Formation of $\mathrm{Ub}-\mathrm{A} \beta$ adducts as a function of the $\mathrm{Ub}: \mathrm{A} \beta$ molar ratio (left graphs) revealed by MALDI-TOF measurements and timedependent variation of their intensities in the presence of IDE (right graphs).

(Fig. 7) in order to calculate the kinetic parameters of the aggregation process (Table S2 in the ESI $\dagger$ ). The amyloid-like aggregation of $\mathrm{A} \beta$ follows a sigmoidal trend, as previously reported. ${ }^{54}$ The lag phase of the self-induced aggregation of $A \beta$ lasts $19.2 \mathrm{~h}$. Such a value significantly increases in the presence of $\mathrm{Ub}$, even when the $\mathrm{Ub}: \mathrm{A} \beta$ molar ratio is $0.2: 1$. The lengthening of the lag phase is proportional to the added amount of $\mathrm{Ub}$ and $t_{\mathrm{lag}}$ becomes more than $60 \mathrm{~h}$ when the $\mathrm{Ub}: \mathrm{A} \beta$ molar ratio is $3: 1$. The maximal fluorescence gain $\left(F_{\max }-F_{0}\right)$, proportional to the extent of fibril formation, has an opposite trend with respect to the concentration of Ub. The $F_{\max }-F_{0}$ value is significantly affected by $\mathrm{Ub}$ when the $\mathrm{Ub}: \mathrm{A} \beta$ molar ratio is equal or higher than $0.2: 1$. The $F_{\max }-F_{0}$ value is

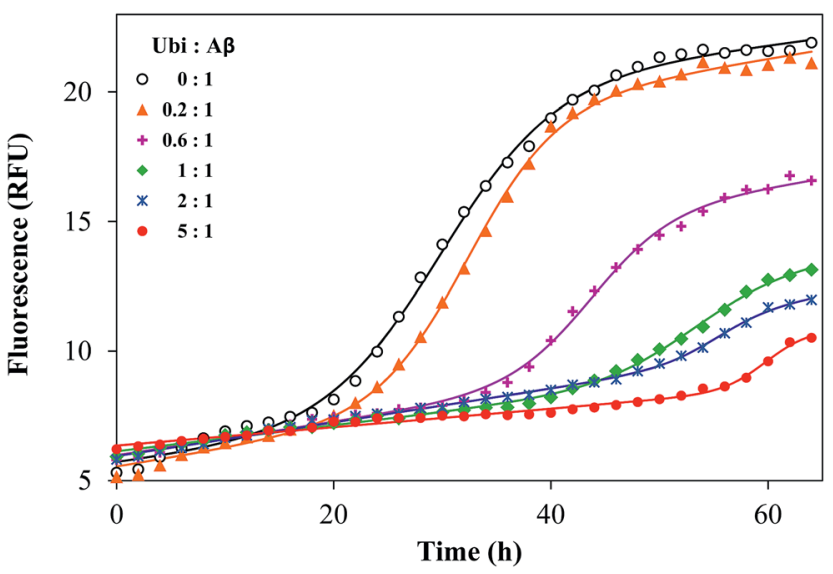

Fig. 7 Representative kinetic profiles of the aggregation of $A \beta 40$ in the presence of ubiquitin, with the $U b: A \beta$ ratio ranging from $0: 1$ to $3: 1$. Solid lines represent the fitted curves for each kinetic profile, whose related parameters are reported in Table S2. $\dagger$
2.2 at the highest ratio tested $(3: 1)$. These data demonstrate that Ub delays the amyloid-type aggregation of $A \beta$ in a dosedependent manner and considerably reduces the extent of the fibril formation. Such an effect might be ascribed to a direct or indirect influence on the $A \beta$ sequence covering the LVFF motif, which is involved in the mechanism of the amyloid aggregation and is a common target of many inhibitors of the $A \beta$ aggregation. ${ }^{55}$ This hypothesis is congruent with the results of the IDEmediated hydrolysis of $\mathrm{A} \beta$ in the presence of $\mathrm{Ub}$.

\section{$A \beta_{1-16}$ inhibits Ub chain growth reactions in tube tests}

In the cell, Ub chain growth is initiated by the Ub-activating enzyme E1, which adenylates the C-terminus of ubiquitin in an ATP-dependent fashion to form a high energy thioester bond by a cysteine residue. Then, $\mathrm{E} 1$ hands the activated Ub over to a conjugating enzyme (E2), forming an E2-Ub complex in proximity of the target protein. The final ubiquitinylation of the substrate occurs through the action of specific E3 ubiquitin ligases. Unanchored (or free) Ub chains (i.e., Ub chains that are not linked to any substrate) are normally considered very useful tools to study ubiquitinylation processes. A number of protocols have been developed to produce K48 and K63-linked free Ub chains in tube tests, ${ }^{56}$ which may be thus considered as a helpful method to single out the capacity of adverse factors in affecting the Ub-conjugation machinery. ${ }^{56}$ Due to its significant affinity for $U b$, it is plausible that $A \beta$ may interfere with the complex cascade of events leading to poly-ubiquitinylation. To address this issue, we have carried out poly-ubiquitinylation reactions in the presence of increasing concentration of $A \beta$. First, we tried to use the full length $A \beta 40$ peptide, but the simultaneous formation of high molecular weight oligomeric species during the ubiquitinylation reactions masked any 


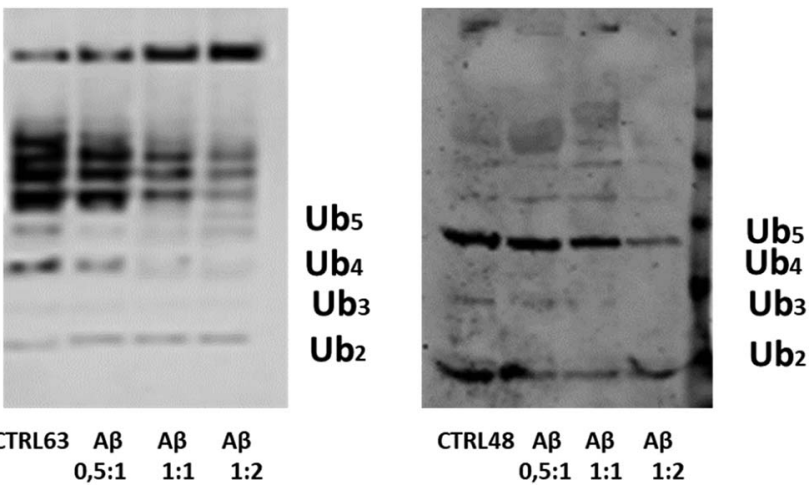

Fig. 8 The WB analysis of $\mathrm{Ub}$ reactions in the presence of the A $\beta 1-16$ peptide, with ratios of $0.5: 1,1: 1$ and $1: 2$ with respect to the $U b$ concentration.

possible effect. Then we used a soluble $\mathrm{A} \beta_{1-16}$ peptide, a fragment that contains all peptide residues that previous experiments consistently identified as Ub binding sites. The $\mathrm{A} \beta_{1-16}$ peptide has been added with a ratio $1: 0.5,1: 1$ and $1: 2$ with respect to Ub to both reaction mixtures (Fig. 8). Western Blot (WB) analysis has shown the dose-dependent inhibitory effect of the $A \beta_{1-16}$ peptide on both Lys48- and Lys-63-linked ubiquitin chain elongation, being already evident at a ratio $1: 1 \mathrm{of} \mathrm{Ub} /$ $A \beta_{1-16}$. These data have further demonstrated that the interaction of $\mathrm{Ub}$ and $\mathrm{A} \beta$ hinders the regions close to the lysine 63 and 48.

\section{Conclusions}

Although accumulation of extracellular amyloid plaques in the brain is widely considered a hallmark of $\mathrm{AD}$, a direct relationship between amyloid load and cognitive decline has never been unequivocally demonstrated. On the other hand, it is becoming increasingly evident that an abnormal rise of intracellular $\mathrm{A} \beta$ levels may be better correlated with neuronal loss and disease progression. Unfortunately, our knowledge of the intracellular chemistry of $\mathrm{A} \beta$ is largely incomplete and there is an urgent need for a more detailed description of the role played by $A \beta$ in the pathological failure of cytosolic protein clearance supervisors like UPS and IDE.

Here, we show that $\mathrm{A} \beta$ has a relatively significant affinity for Ub. It forms $1: 1$ protein-protein complexes mostly involving the C-terminal tail and the $\beta 1 / \beta 2$ loop of Ub. Next, consistent with many reports showing that Ub is often recognized by binding proteins through the hydrophobic surface encompassing residues Leu8, Ile44, His 68 and Val $70,{ }^{57}$ non-covalent interactions involving the central hydrophobic cluster of $A \beta 40$ and the Ub Ile44 were also observed. The residue D1 of the peptide was found to be linked to the K48 and K63 residues of Ub. These two Ub residues were also found to be in contact with residues $\mathrm{S} 8$ and $\mathrm{Y} 10$ of $\mathrm{A} \beta 40$. The $\mathrm{N}$-terminal segment of $\mathrm{A} \beta 40$ (residues D1 E3 and R5) interacts with the Ub C-terminal domain and in particular with residues Lys63 and Glu64. Consistent with the observation that Lys48 and Lys63 residues are buried upon interaction with the $\mathrm{N}$-terminal domain of $\mathrm{A} \beta$, we have also observed that the water soluble fragment $\mathrm{A} \beta_{1-16}$ significantly inhibits Ub chain growth in tube tests. It is noteworthy that the $A \beta / \mathrm{Ub}$ interaction resembles non covalent contacts between Ub and Ub binding domains (UBDs) which are important players in Ub chain growth and signaling. For example, most of the known UBDs are predominantly $\alpha$-helical and bind the Ile44 hydrophobic patch of Ub. ${ }^{58}$ Moreover, most of the UBDs exhibit binding affinities $\left(K_{\mathrm{d}}\right)$ in the range between 2 and $500 \mu \mathrm{M} \cdot{ }^{41} \mathrm{Next}, \mathrm{A} \beta_{40}$ may assume an $\alpha$-helical structure in its central hydrophobic cluster (residues 14-20) upon interaction with Ub. Besides these hydrophobic contacts, salt bridges connecting the D1 residue of $\mathrm{A} \beta 40$ with $\mathrm{K} 63$ and $\mathrm{K} 48$ of Ub are also evident. This coupled electrostatic/hydrophobic interaction likely explains the evident binding affinity of $\mathrm{A} \beta$ for Ub and may explain why the peptide is a competitive Ub binding protein. Furthermore, while on one side $\mathrm{A} \beta$ binding to Ub compromises its ability to recognize physiological binding partners, on the other side it significantly influences peptide secondary structure and ability to self-assemble into amyloid-like aggregates and to be degraded by IDE. The reduced propensity of A $\beta 40$ to aggregate into amyloid fibrils is ascribable to the increased $\alpha$ helical content observed in the Ub-bound peptide. This ability of Ub to mold poorly structured peptides has been already observed in previous reports. ${ }^{30}$ Remarkably, Ub/A $\beta$ interactions also have a site-specific effect on the IDE-mediated degradation process of the amyloid peptide with possible consequences on the toxicity of the hydrolyzed $A \beta$ fragments. ${ }^{59}$ Conclusively, these results evidence how the non-covalent interaction between $\mathrm{A} \beta 40$ and $\mathrm{Ub}$ may have important consequences in the regulation of the upstream events of the UPS and in IDEmediated clearance pathways. These results may hopefully pave the way to future studies addressing the multifaceted role played by the altered $\mathrm{A} \beta$ homeostasis occurring in $\mathrm{AD}$.

\section{Author contribution}

F. B. performed IDE-mediated hydrolysis studies; V. L. and S. G. V. performed polyubiquitination reactions; I. M. M. A. performed MALDI-TOF studies; A. P. performed molecular simulations; C. I. performed cross-linking studies; G. M., G. D. A and R. F. performed NMR studies; V. G. N. performed ELISA assays; D. S. and G. R. T. contributed to cell studies; M. C. wrote the paper; D. C. performed SPR experiments; L. P. and E. P. performed MST experiments; G. G. analyzed SPR data and designed the research; D. M. designed the research and wrote the paper.

\section{Conflicts of interest}

There are non conflicts of interest to declare.

\section{Acknowledgements}

This work was financially supported by the Italian MiUR (PRIN 20157WZM8A). C. I. is grateful to Prof. Andrea Sinz for continuous support. 


\section{References}

1 D. J. Selkoe, Neuron, 1991, 6, 487-498.

2 E. Terzi, G. Hölzemann and J. Seelig, Biochemistry, 1997, 36, 14845-14852.

3 B. A. Yankner, L. K. Duffy and D. A. Kirschner, Science, 1990, 250, 279-282.

4 J. A. Hardy and G. A. Higgins, Science, 1992, 256, 184.

5 I. Benilova, E. Karran and B. De Strooper, Nat. Neurosci., 2012, 15, 349.

6 K. P. Kepp, Prog. Neurobiol., 2016, 143, 36-60.

7 O. Wirths and T. A. Bayer, Life Sci., 2012, 91, 1148-1152.

8 C. Schmitz, B. P. Rutten, A. Pielen, S. Schäfer, O. Wirths, G. Tremp, C. Czech, V. Blanchard, G. Multhaup and P. Rezaie, Am. J. Pathol., 2004, 164, 1495-1502.

9 G. Grasso, A. M. Santoro, V. Lanza, D. Sbardella, G. R. Tundo, C. Ciaccio, S. Marini, M. Coletta and D. Milardi, Coord. Chem. Rev., 2017, 347, 1-22.

10 A. Ciechanover and Y. T. Kwon, Exp. Mol. Med., 2015, 47, e147.

11 S. Vijay-Kumar, C. E. Bugg and W. J. Cook, J. Mol. Biol., 1987, 194, 531-544.

12 C. M. Pickart and D. Fushman, Curr. Opin. Chem. Biol., 2004, 8, 610-616.

13 D. A. Nijholt, T. R. de Graaf, E. S. van Haastert, A. O. Oliveira, C. R. Berkers, R. Zwart, H. Ovaa, F. Baas, J. J. Hoozemans and W. Scheper, Cell Death Differ., 2011, 18, 1071.

14 L. Gregori, C. Fuchs, M. E. Figueiredo-Pereira, W. E. Van Nostrand and D. Goldgaber, J. Biol. Chem., 1995, 270, 19702-19708.

15 L. Gregori, J. F. Hainfeld, M. N. Simon and D. Goldgaber, J. Biol. Chem., 1997, 272, 58-62.

16 M. L. Salon, L. Pasquini, M. B. Moreno, J. M. Pasquini and E. Soto, Exp. Neurol., 2003, 180, 131-143.

17 S. Song, S.-Y. Kim, Y.-M. Hong, D.-G. Jo, J.-Y. Lee, S. M. Shim, C.-W. Chung, S. J. Seo, Y. J. Yoo and J.-Y. Koh, Mol. Cell, 2003, 12, 553-563.

18 S. Oh, H. S. Hong, E. Hwang, H. J. Sim, W. Lee, S. J. Shin and I. Mook-Jung, Mech. Ageing Dev., 2005, 126, 1292-1299.

19 C. G. Almeida, R. H. Takahashi and G. K. Gouras, J. Neurosci., 2006, 26, 4277-4288.

20 B. P. Tseng, K. N. Green, J. L. Chan, M. Blurton-Jones and F. M. LaFerla, Neurobiol. Aging, 2008, 29, 1607-1618.

21 X. Zhao and J. Yang, ACS Chem. Neurosci., 2010, 1, 655-660.

22 A. V. Morozov, A. A. Kulikova, T. M. Astakhova, V. A. Mitkevich, K. M. Burnysheva, A. A. Adzhubei, P. A. Erokhov, M. B. Evgen'ev, N. P. Sharova and V. L. Karpov, J. Alzheimer's Dis., 2016, 54, 763-776.

23 J. Lowe, A. Blanchard, K. Morrell, G. Lennox, L. Reynolds, M. Billett, M. Landon and R. J. Mayer, J. Pathol., 1988, 155, 9-15.

24 A. Ciechanover and P. Brundin, Neuron, 2003, 40, 427-446. 25 A. Hershko and A. Ciechanover, Annu. Rev. Biochem., 1998, 67, 425-479.

26 J. D. Wright, P. D. Mace and C. L. Day, Trends Biochem. Sci., 2016, 41, 924-937.
27 G. R. Tundo, D. Sbardella, C. Ciaccio, G. Grasso, M. Gioia, A. Coletta, F. Polticelli, D. Di Pierro, D. Milardi and P. Van Endert, Crit. Rev. Biochem. Mol. Biol., 2017, 52, 554-582.

28 M. F. Sciacca, V. Romanucci, A. Zarrelli, I. Monaco, F. Lolicato, N. Spinella, C. Galati, G. Grasso, L. D'Urso and M. Romeo, ACS Chem. Neurosci., 2017, 8, 1767-1778.

29 G. Arena, R. Fattorusso, G. Grasso, G. I. Grasso, C. Isernia, G. Malgieri, D. Milardi and E. Rizzarelli, Chem.-Eur. J., 2011, 17, 11596-11603.

30 V. Lanza, A. Travaglia, G. Malgieri, R. Fattorusso, G. Grasso, G. Di Natale, V. Zito, G. Arena, D. Milardi and E. Rizzarelli, Chem.-Eur. J., 2016, 22, 17767-17775.

31 T. Ebendal, J. Neurosci. Res., 1992, 32, 461-470.

32 J. S. Elam, S. T. Thomas, S. P. Holloway, A. B. Taylor and P. J. Hart, Adv. Protein Chem., 2002, 60, 151-219.

33 L. Aloe, L. Bracci-Laudiero, S. Bonini, L. Manni and L. Aloe, Allergy, 1997, 52, 883-994.

34 S. Vivekanandan, J. R. Brender, S. Y. Lee and A. Ramamoorthy, Biochem. Biophys. Res. Commun., 2011, 411, 312-316.

35 A. Sinz, Mass Spectrom. Rev., 2006, 25, 663-682.

36 J. Rappsilber, J. Struct. Biol., 2011, 173, 530-540.

37 A. Leitner, T. Walzthoeni, A. Kahraman, F. Herzog, O. Rinner, M. Beck and R. Aebersold, Molecular \& Cellular Proteomics, 2010. 38 C. Iacobucci, S. Reale and F. De Angelis, ChemBioChem, 2013, 14, 181-183.

39 M. Q. Müller, F. Dreiocker, C. H. Ihling, M. Schäfer and A. Sinz, Anal. Chem., 2010, 82, 6958-6968.

40 C. Iacobucci, M. Götze, C. H. Ihling, C. Piotrowski, C. Arlt, M. Schäfer, C. Hage, R. Schmidt and A. Sinz, Nat. Protoc., 2018, 13, 2864-2889.

41 K. Sokratous, L. V. Roach, D. Channing, J. Strachan, J. Long, M. S. Searle, R. Layfield and N. J. Oldham, J. Am. Chem. Soc., 2012, 134, 6416-6424.

42 R. J Baranello, K. L Bharani, V. Padmaraju, N. Chopra, D. K. Lahiri, N. H. Greig, M. A. Pappolla and K. Sambamurti, Curr. Alzheimer Res., 2015, 12, 32-46.

43 L. A. McCord, W. G. Liang, E. Dowdell, V. Kalas, R. J. Hoey, A. Koide, S. Koide and W.-J. Tang, Proc. Natl. Acad. Sci. U. S. A., 2013, 110, 13827-13832.

44 F. Bellia and G. Grasso, J. Mass Spectrom., 2014, 49, 274-279. 45 F. Bellia, A. Pietropaolo and G. Grasso, J. Mass Spectrom., 2013, 48, 135-140.

46 G. R. Tundo, E. Di Muzio, C. Ciaccio, D. Sbardella, D. Di Pierro, F. Polticelli, M. Coletta and S. Marini, The FEBS J., 2016, 283, 3755-3770.

47 G. Tundo, C. Ciaccio, D. Sbardella, M. Boraso, B. Viviani, M. Coletta and S. Marini, PloS One, 2012, 7, e34376.

48 V. Lanza, F. Bellia and E. Rizzarelli, Coord. Chem. Rev., 2018, 369, 1-14.

49 G. Grasso, E. Rizzarelli and G. Spoto, Biochim. Biophys. Acta, Proteins Proteomics, 2008, 1784, 1122-1126.

50 S. Oddo, A. Caccamo, L. Tran, M. P. Lambert, C. G. Glabe, W. L. Klein and F. M. LaFerla, J. Biol. Chem., 2006, 281, 1599-1604.

51 S. A. Kotler, P. Walsh, J. R. Brender and A. Ramamoorthy, Chem. Soc. Rev., 2014, 43, 6692-6700. 
52 M. F. M. Sciacca, C. Tempra, F. Scollo, D. Milardi and C. La Rosa, Biochim. Biophys. Acta, Biomembr., 2018, 1860, 1625-1638.

53 F. Scollo, C. Tempra, F. Lolicato, M. F. Sciacca, A. Raudino, D. Milardi and C. La Rosa, J. Phys. Chem. Lett., 2018, 9, 5125-5129.

54 G. I. Grasso, G. Arena, F. Bellia, E. Rizzarelli and G. Vecchio, J. Inorg. Biochem., 2014, 131, 56-63.

55 V. Oliveri, S. Zimbone, M. L. Giuffrida, F. Bellia, M. F. Tomasello and G. Vecchio, Chem.-Eur. J., 2018, 24, 6349-6353.
56 C. M. Pickart and S. Raasi, in Methods in Enzymology, Academic Press, 2005, vol. 399, pp. 21-36.

57 D. Komander and M. Rape, Annu. Rev. Biochem., 2012, 81, 203-229.

58 J. H. Hurley, S. Lee and G. Prag, Biochem. J., 2006, 399, 361372.

59 A. Zhang, W. Qi, T. A. Good and E. J. Fernandez, Biophys. J., 2009, 96, 1091-1104. 